\title{
American Woodcock Migration Ecology: Factors Influencing Departure Rates and Habitat Selection at Cape May, New Jersey
}

BRIAN B. ALLEN, ${ }^{1}$ University of Maine, Department of Wildlife, Fisheries, and Conservation Biology, Orono, ME 04469, USA

DANIEL G. MCAULEY, U.S. Geological Survey, Patuxent Wildlife Research Center, Orono, ME 04469, USA

RAYMOND E. BROWN, U.S. Fish and Wildlife Service, Moosehorn National Wildlife Refuge, Calais, ME 04694, USA

CHRIS DWYER, U.S. Fish and Wildlife Service, Div. of Migratory Birds, Hadley, MA o1035, USA

ERIK J. BLOMBERG, University of Maine, Department of Wildlife, Fisheries, and Conservation Biology, Orono, ME 04469, USA

\begin{abstract}
Migration may expose birds to hazards at intensities greater than those during any other life stage, and effective conservation of migratory species requires an understanding of space use during migration. From 2010 to 2013 we conducted a radio-telemetry study of American woodcock (Scolopax minor) on the Cape May Peninsula, New Jersey, which is an important stopover site for migratory woodcock in the eastern flyway. Our research objectives were to 1) describe diurnal cover-type characteristics used by woodcock, 2) evaluate second-order habitat selection during the fall migration period, 3) evaluate drivers affecting timing of departure of woodcock from stopover sites, and 4) determine age- and sexspecific departure rates. We nightlighted fields to capture birds and attach VHF radio-transmitters. Over 4 years we radiomarked 271 woodcock and collected 1,949 GPS point locations from these birds (Range $=0-21$ points per individual). We used GIS and resource selection functions in the form of generalized linear mixed models to compare land cover-type attributes at the marked locations (used) to attributes at random locations distributed across our study landscape (available). Our model shows a strong negative effect on selection as distance from fields increases, avoidance of large contiguous forest, and selection for forested wetlands. We used results from this analysis to develop a predictive model of habitat distribution at Cape May. To complete objective 3 and 4 we used a CJS survival analysis framework, where results from objectives 1 and 2, as well as weather and astrological variables, were used as covariates to model timing of departure. Our study improves understanding of American woodcock habitat selection during this critical life stage and provides a predictive model for understanding timing of departure from a migratory stopover. Furthermore, our results may identify important habitats for other short-distance migrants that rely on early successional habitat.
\end{abstract}

Proceedings of the American Woodcock Symposium 11: 122

KEY WORDS: American woodcock, habitat selection, migration ecology, New Jersey, predictive model

1 email: brian.allen@maine.edu 